\title{
Potential mechanisms of resistance to the modern fluorinated 4-quinolones
}

\author{
C. S. LEWIN, RUTH A. ALLEN and S. G. B. AMYES
}

Department of Bacteriology, Medical School, Edinburgh University, Teviot Place, Edinburgh EH8 9AG

\section{Introduction}

The 4-quinolones are unlike most agents of antimicrobial chemotherapy in that they are chemically synthesised compounds rather than naturally occurring products. The principal target of this class of drugs is the enzyme DNA gyrase (E.C. number 5.99.1.3) which is the only bacterial enzyme capable of introducing negative supercoils into DNA. ${ }^{1-3}$ DNA supercoiling plays an important role in bacterial metabolism because not only does it compact the chromosome but also it is involved in the regulation of gene transcription. ${ }^{4,5}$

DNA gyrase is a tetrameric enzyme consisting of two A and two B subunits. ${ }^{6,7}$ The A subunit cuts both strands of DNA simultaneously at intervals four base-pairs apart and holds the strands apart but covalently bound to the enzyme. ${ }^{8}$ The B subunit, with ATP used for energy, then introduces a negative supercoil into the DNA ${ }^{9}$ and the A subunit then reseals the two strands. The 4-quinolones appear to bind to the $A$ subunit and prevent the resealing of the DNA strands. ${ }^{10}$. The ability of DNA gyrase to break both DNA strands simultaneously means that not only is it able to supercoil DNA but also it can catenate and decatenate DNA and, hence, is involved in segregation of the daughter chromosomes after replication. ${ }^{11}$

Although the 4-quinolones have been known for more than 25 years, their clinical use has been fairly limited until recently because of their narrow spectrum of activity and poor pharmacokinetics. The first therapeutically useful 4-quinolone synthesised was nalidixic acid ${ }^{12}$ the antimicrobial spectrum of which was limited to Enterobacteriaceae. Nalidixic acid has proved clinically useful in the treatment of urinary-tract and enteric infections. ${ }^{13,14}$ Over the past ten years there has been renewed interest in this class of antimicrobial

Received 19 June 1989; accepted 3 Aug. 1989. agents spurred by the discovery that the addition of a piperazine side chain at $\mathrm{C} 6$ and fluorine at $\mathrm{C} 7$ to the common 4-oxo-1,4-dihydroquinoline skeleton caused a 1000-fold improvement in the antimicrobial activity of the compounds compared with the older drugs in this class. Thus, bacterial species hitherto refractory to the 4-quinolones were now within the compass of their therapy. Drugs such as pefloxacin, norfloxacin, ciprofloxacin, enoxacin and ofloxacin have been shown to be active against a wide range of clinical isolates at clinically achievable levels ${ }^{15}$ and are now available for use in various parts of the world. These new 4-quinolones appear to represent a significant advance in the control of bacterial infection. However, the ability of bacteria to develop resistance to the modern 4quinolones will be a crucial factor in the ultimate success of this class of antimicrobial agents.

\section{Plasmid-mediated 4-quinolone resistance}

Bacterial resistance to an antimicrobial agent is usually mediated either via a plasmid-encoded factor or a chromosomal mutation. Plasmids are molecules of extrachromosomal DNA that can replicate independently of the chromosome and may be freely transferred between bacteria including those of different species. Plasmids can mediate antibacterial resistance by one of three mechanisms: (i) inactivation of the drug, e.g., the $\beta$ lactams; (ii) production of an additional target resistant to the antimicrobial agent, e.g., trimethoprim; (iii) active efflux of the drug from the cell, e.g., tetracycline.

It is usual for plasmids to carry a number of genes conferring resistance to many antibiotics. As a result of this, plasmids are usually the main carriers of resistance in many clinical bacteria and are a major cause of concern because they may lead to the rapid world-wide spread of resistance. ${ }^{16}$

Plasmid-mediated resistance to the modern 4- 
quinolones has not yet been identified. In the past few years two examples of plasmid-mediated nalidixic-acid resistance have been reported in Shigella dysenteriae strains isolated in $\mathrm{Kashmir}^{17}$ and in Bangladesh. ${ }^{18}$ However, neither report proved conclusively that nalidixic-acid resistance was transferable because they did not demonstrate that the resistance gene could be successively transferred from strain to strain. Indeed, whether the resistance to nalidixic acid was actually conferred by the plasmid has been questioned. ${ }^{19}$ Furthermore, neither of these plasmid-encoded nalidixic acid-resistance genes conferred resistance to the modern 4-quinolones, although one did appear to increase the frequency of resistance to ciprofloxacin. ${ }^{18}$ This fact has revealed the possibility that these plasmids may not actually carry a gene coding for nalidixic-acid resistance but rather are mutator plasmids increasing the frequency of chromosomal mutations to nalidixic-acid resistance. It has been suggested that this may explain the association of plasmids with nalidixic-acid resistance in Sh. dysenteriae strains isolated from Zaire. ${ }^{20}$

From our previous knowledge it is difficult to envisage the mechanism by which plasmid-mediated 4-quinolone resistance could be expressed. The most likely mechanism would seem to be some sort of reduction of permeability. A drug-destruction mechanism appears unlikely as the 4-quinolones are synthetic agents and it seems unlikely, although possible, that an enzyme which destroys the drug exists. ${ }^{21}$ A 4-quinolone-resistant DNA gyrase encoded by a plasmid would also seem an unlikely candidate to confer 4-quinolone resistance because genetic studies have shown that quinolone sensitivity is dominant over quinolone resistance in gyrase genes. $^{22-24}$

Not only has plasmid-mediated resistance to the modern 4-quinolones not been identified but some bacteria containing $\mathrm{R}$-plasmids have been shown to be hypersensitive to the 4-quinolones. ${ }^{25}$ Furthermore, the 4-quinolones appear to be plasmid-curing agents both in vitro ${ }^{26-28}$ and in vivo. ${ }^{29,30}$ However, despite the clinical reports of plasmid curing by the 4-quinolones, ${ }^{29,} 30$ the actual clinical relevance of this plasmid-curing ability must be questioned as it seems unlikely that total elimination of plasmids could ever occur. ${ }^{28,31}$ The mechanism by which 4quinolones eliminate plasmids may involve the selection of plasmid-free cells, as is the case with novobiocin, ${ }^{32}$ or, alternatively, plasmid replication may be more sensitive to the changes in supercoiling caused by the drugs than chromosomal replication. ${ }^{33}$

\section{Chromosomally-mediated 4-quinolone resistance}

The only mechanism by which bacteria are able to develop resistance to these antimicrobial agents is through chromosomal mutations and it has been shown that chromosomally-mediated resistance to the 4-quinolones occurs by one of two mechanisms: either an alteration in the target enzyme, DNA gyrase; or a mutation causing a reduction in the permeability of the cell for the drug. ${ }^{21,31}$

\section{Alterations in DNA gyrase}

In most species investigated so far, high-level resistance to all 4-quinolones appears to be conferred by mutations in the $g y r A$ gene which codes for the A subunit of DNA gyrase thought to be the target of the 4-quinolones. ${ }^{3,31}$ gyrA mutations confer high-level cross-resistance to all 4-quinolones but do not seem to be associated with resistance to antibacterial agents which are unrelated to these drugs. Such mutations have been identified in Escherichia coli $(c f x A$, gyrA, nalA, nfxA), 24,34-36 Pseudomonas aeruginosa (nalA, cfxA $),{ }^{37-40}$ Haemophilus influenzae, ${ }^{41}$ Citrobacter freundii ${ }^{42}$ and Serratia marcescens..$^{43}$ An exception to this rule may be Bacteroides fragilis for which Kato et al. ${ }^{44}$ have reported that high-level resistance appears to be linked to a permeability change rather than to an alteration in the gyrA gene.

The gyr $A$ genes of $E$. coli strain KL16 and of four spontaneous quinolone-resistant mutants of this strain have been mapped. ${ }^{45}$ The mutations which conferred quinolone resistance were all found to be within a small region near the $\mathrm{N}$-terminus of the gyr $A$ gene at nucleotides 248,318 and $199 .{ }^{45}$ The amino-acid substitutions in the $A$ subunit were serine to leucine or tryptophan, glutamine to histidine, and alanine to serine (at amino acids 83 , 106 and 67, respectively). ${ }^{45}$ Recently, the gyr $A$ gene of a clinical isolate of $E$. coli was sequenced and the amino-acid substitution was also at amino acid $83 .{ }^{45 a}$ It is interesting to note that all of these mutations are situated close to Tyr at amino acid 122 of the A subunit which has been shown to be the site, in DNA gyrase, that is covalently bound to DNA when the enzyme breaks the phosphodiester bonds of DNA. ${ }^{46}$ However, until the threedimensional structure of DNA gyrase has been determined the significance of this observation is unclear.

Mutations in the B subunit of DNA gyrase encoded by the $g y r B$ gene may also affect bacterial susceptibility to the 4-quinolones. The na131 
mutation $^{47}$ (also known as the nalC mutation ${ }^{48}$ ) and the nal 24 mutation, ${ }^{47}$ are point mutations in the gyrB gene that cause changes at amino acids 426 and 447 in the B subunit of DNA gyrase. ${ }^{47}$ Both mutations are in the region which Cozzarelli ${ }^{7}$ has postulated is involved in binding of the $B$ subunit to the A subunit. The na124 mutation causes the substitution of asparagine for aspartic acid whilst the na131 mutation involves a change from lysine to glutamic acid. ${ }^{47}$ Both these aminoacid substitutions cause a change in the overall charge of the B subunit; the nal24 mutation decreases the negative charge of the protein, whereas the na131 mutation has the opposite effect and increases the negative charge. This difference may explain the observation by $\mathrm{Smith}^{49}$ that the na131 mutation confers resistance only to 4quinolones that lack a $\mathrm{C} 7$ piperazine substituent, whilst rendering bacteria hypersensitive to 4quinolones possessing a $\mathrm{C} 7$ piperazine. It has been suggested that this dichotomy results from the ability of the nal31 mutant strain to increase the negative charge on the B subunits of DNA gyrase, leading then to an increase in the attraction of the B subunit for the positively-charged piperazine group. ${ }^{31,47}$

Most of the investigations of the effect of 4quinolones on DNA-gyrase activity have been carried out with gram-negative bacteria and there have been comparatively few investigations done with gram-positive bacteria. It has been suggested from results obtained with Micrococcus luteus ${ }^{50,51}$ and Staphylococcus aureus ${ }^{52}$ that the DNA gyrases of gram-positive bacteria may inherently be much less susceptible to the modern 4-quinolones. However, Takahata and Nishino ${ }^{53}$ found that ciprofloxacin, norfloxacin and ofloxacin can inhibit the supercoiling activity of DNA gyrase from Staph. aureus and, therefore, it remains unclear how susceptible the DNA gyrase of gram-positive - bacteria is to inhibition by the modern 4-quinolones.

\section{4-quinolone resistance resulting from impermeability mechanisms}

The ability of antimicrobial agents to penetrate bacteria is an important factor in their spectrum and activity. Therefore, reducing the ability of the 4-quinolones to penetrate into bacteria might decrease bacterial susceptibility to these drugs. The 4-quinolones penetrate bacteria by diffusion through the phospholipid bilayer and porins in the outer membrane of gram-negative bacteria. The hydrophobicity of the drug has an effect on its ability to diffuse across the phospholipid bilayer of the membrane. The more hydrophilic the drug, the less able it is to penetrate the bacterium through the phospholipid bilayer. ${ }^{54-57}$ The recent discovery of endogenous active-efflux of norfloxacin at the inner membrane of $E$. coli and $P$. aeruginosa $a^{58-60}$ suggests that the factors determining the entry of fluoroquinolones into bacteria may be more complicated than previously thought.

Mutations affecting 4-quinolone permeability have been identified in $E$. coli (nalB, $n f x B$, nor $B$, cf $x B$ ), ${ }^{21,34,60,61}$ Salmonella, ${ }^{54}$ Pseudomonas (nalB, cf $x B$ and $n f x B, q r 1, q r 2),{ }^{37,38,40,59,62}$ Klebsiella and Serratia. ${ }^{63-66}$ Unlike mutations in the gyr $A$ or $g y r B$ genes, which confer cross-resistance to other 4quinolones only but not to unrelated antibacterial agents, mutations affecting 4-quinolone uptake may be associated with cross-resistance to unrelated antibacterial agents, such as tetracycline, chloramphenicol, the aminoglycosides and $\beta$-lactams. The impermeability mechanisms rendering bacteria resistant to the 4-quinolones have been extensively investigated in $E$. coli and in $P$. aeruginosa.

\section{Impermeability in E. coli}

Mutations in $E$. coli that confer resistance to the 4-quinolones by an impermeability mechanism appear to be associated with alterations in outermembrane porin $\mathrm{F}$ (ompF), a protein coded by the $o m p F$ gene. Inactivation of the $o m p F$ gene results in resistance to the 4-quinolones. ${ }^{56-58}$ It is interesting to note that resistance resulting in alterations of the $o m p F$ porin has less effect on bacterial susceptibility to nalidixic acid than to the modern fluorinated drugs. ${ }^{54}$ This is probably because nalidixic acid, which is more hydrophobic than the modern drugs, is able to penetrate bacteria through the lipid bilayer as well as by the $o m p F$ porin.

Resistance to the 4-quinolones in E. coli may be mediated not only by an alteration in the ompF gene itself but also by mutations in regulatory genes controlling expression of $o m p F$ at a post-transcriptional level. Two mutations, $n f x B$ mapping at $19 \min ^{34,60}$ and $c f x B$ or nor $B$ mutations mapping at $34 \mathrm{~min},{ }^{21,60,61}$ have been shown to decrease $o m p F$ expression, although they do not map in the region of the $o m p F$ gene (which maps at $21 \mathrm{~min}$ ). Again, $c f x B$ appears to be an allele of the mar $A$ gene which confers resistance to tetracyclines and chloramphenicol as well as to the 4-quinolones. ${ }^{21,60,67,68}$ Hooper et al..$^{60}$ have suggested that the molecular mechanism results from the coding of a factor by mar $A$ which negatively regulates $o m p F$ expression. They suggest that $c f x B$ is a 
mutation which leads to an increase in the expression of this factor because $c f x B$ is dominant over cf $x B+{ }^{60}$

Although $n f x B$ is not an allele of $\operatorname{mar} A$, it is also associated with this gene because a functional mar $A$ gene is required for an $n f x B$ mutant to remain viable. ${ }^{60}$ However, whether $n f x B$ functions as a positive or negative regulator of $o m p F$ expression is not known.

Alterations of the outer-membrane proteins are not the only impermeability mechanism leading to 4-quinolone resistance. Changes in the lipopolysaccharides of the outer membrane are also associated with resistance. ${ }^{61,69}$ The nor $C$ mutation mapping at $8 \mathrm{~min}$ on the $E$. coli chromosome near the lac operon confers resistance to the 4-quinolones norfloxacin and ciprofloxacin as well as the $\beta$ lactam cefoxitin. However the nor $C$ mutation also confers hypersusceptibility to hydrophobic drugs such as nalidixic acid, cloxacillin and novobiocin and to sodium dodecyl sulphate. ${ }^{61}$ Phage-susceptibility tests indicate that the nor $C$ mutation causes alterations in the lipopolysaccharide layer and $o m p F{ }^{61}$ However, it remains unclear how nor $C$ and the $o m p F$ protein interact. The hydrophobicity of the cell surface of the nor $C$ mutant was also increased. The nor $C$ mutation also appears to reduce levels of a second outer-membrane protein, ompC. ${ }^{61}$

4-Quinolone resistance resulting from reduced drug uptake in $E$. coli may not be mediated solely by alterations in the outer-membrane proteins or phospholipid bilayer, as had been previously thought. ${ }^{31,52}$ Cohen et al. ${ }^{58}$ demonstrated a system in which norfloxacin may be actively pumped out of $E$. coli at the inner membrane. This suggests that 4-quinolone resistance resulting from decreased drug permeability is not caused solely by decreased diffusion of the drugs across the outer membrane but may be magnified by the active-efflux system at the inner membrane. ${ }^{58,60}$ Whether this activeefflux system is specific to norfloxacin or affects other 4-quinolones has not yet been elucidated. ${ }^{60}$ However, other workers have found that energy inhibitors have little effect on the uptake of enoxacin and fleroxacin by $E$. coli $i^{56,57}$ suggesting that active efflux at the inner membrane may not involve all 4quinolones. Hooper et al. ${ }^{60}$ have proposed that the discovery of this active-efflux system for norfloxacin suggests that another class of drug mutations causing 4-quinolone resistance may exist. This mechanism would be similar to tetracycline-resistance in which the drug-efflux system works with enhanced efficiency ${ }^{70}$ and, if the tetracyclineresistance analogy is continued, opens the possibil- ity of a plasmid-mediated 4-quinolone-resistance mechanism resulting from a drug-efflux system.

\section{Impermeability in P. aeruginosa}

In $P$. aeruginosa 4-quinolone resistance has also been shown to be associated with alterations in outer-membrane proteins that may lead to crossresistance to unrelated antibacterial agents. ${ }^{37,40,62}$ As with $E$. coli, some of these alterations in outermembrane proteins confer less resistance to nalidixic acid than to the modern 4-quinolones. However, unlike $E$. coli, 4-quinolone resistance in $P$. aeruginosa does not appear to be associated with alterations in a specific outer-membrane protein but rather with alterations in a wide range of outermembrane proteins. ${ }^{37,40,59,62}$

Although resistance to the 4-quinolones in $P$. aeruginosa has been associated with the loss of outer-membrane protein $F^{62}$ alterations in a wide range of other outer-membrane proteins have also been described in 4-quinolone-resistant strains. Both the $c f x B$ and nalB mutations caused alterations in the outer-membrane profile that were not related to $o m p F^{40}$ whilst Daikos et al. ${ }^{71}$ and Legakis et $a l .^{72}$ found that unstable low-level resistance to the 4-quinolones in $P$. aeruginosa was associated with the alteration or loss of a $31-32-\mathrm{Kda}$ outermembrane protein. However, unlike the $o m p F$ and $c f x B$ mutations in $P$. aeruginosa, the loss or alteration of this $31-32-\mathrm{Kda}$ protein did not confer cross-resistance to antibacterial agents which were unrelated to the 4-quinolones. ${ }^{71}$ Chamberland $e t$ $a l .{ }^{59}$ found that low-level resistance to the 4quinolones in $P$. aeruginosa $(\mathrm{Qr} 1, \mathrm{Qr} 2)$ was associated with a reduction in the amount of outermembrane protein $\mathrm{G}(\mathrm{omp} G)$ and an antigenically related $40-\mathrm{Kda}$ outer-membrane protein. The relationship and function of these two proteins is unclear but the alterations conferred resistance to some $\beta$-lactams, chloramphenicol and tetracycline as well as to the 4-quinolones. ${ }^{59}$

4-Quinolone resistance in $P$. aeruginosa is associated not only with the decreased expression of outer-membrane proteins but also with the appearance of a new protein. Hirai et al. ${ }^{38}$ demonstrated by sodium dodecyl sulphate-polyacrylamide gel electrophoresis of outer-membrane proteins that norfloxacin resistance in the $P$. aeruginosa $n f x B$ mutant strain was associated with the appearance of a 54-Kda protein. However, unlike the nalB and $c f x B$ mutations, the $n f x B$ mutation did not confer resistance to the $\beta$-lactams or the aminoglycosides. On the contrary, it rendered the bacteria hypersusceptible to these drugs. ${ }^{38}$ Furthermore, the $n f x B$ 
mutation also had no effect on the susceptibility of the strain to chloramphenicol and tetracycline ${ }^{38}$ whereas the $c f x B$ mutation ${ }^{40}$ (but not the nalB mutation ${ }^{37}$ ) conferred resistance to both these drugs. Robillard and Scarpa ${ }^{40}$ have reported that they had observed a mutation which conferred a similar antibiotic-resistance pattern to $n f x B$ in a ciprofloxacin-resistant derivative of $P$. aeruginosa. However, although the mutation was associated with the appearance of a new outer-membrane protein, the size of this protein was not given. ${ }^{40}$ Legakis et al. ${ }^{72}$ reported ciprofloxacin resistance associated with the increased production of a 54$\mathrm{Kda}$ outer-membrane protein rather than the appearance of a new protein. This mutant strain was also cross-resistant to $\beta$-lactams and aminoglycosides and, therefore, its mutation would seem to differ from the $n f x B$ mutation. Hence, unlike $E$. coli, resistance to the 4-quinolones in $P$. aeruginosa caused by changes in outer-membrane proteins is associated not only with alterations, reduced expression or loss of a protein but also with the increased expression of a protein or even the appearance of a new protein.

Finally, a mutation similar to the nor $C$ mutation in $E$. coli ${ }^{61}$ has also been identified in $P$. aeruginosa that does not result solely from changes in the outermembrane proteins. Legakis et al. ${ }^{72}$ identified ciprofloxacin-resistant $P$. aeruginosa with alterations in the expression of lipopolysaccharides as well as outer-membrane proteins.

\section{Impermeability in other species}

Resistance to the 4-quinolones in Klebsiella, Enterobacter and Serratia spp. resulting from reduced drug uptake has also been associated with alterations in the outer-membrane proteins. ${ }^{63-65}$ However, impermeability mutants have not yet been identified in gram-positive bacteria. It has been suggested by Smith and Lewin ${ }^{31}$ that this may be because gram-positive bacteria lack an outer membrane and that that deficiency of an outer membrane, and its associated porins, may be advantageous to bacteria with respect to their susceptibility to these antibacterial agents. However, recently, ciprofloxacin resistance in Staph. aureus has been reported to result from reduced access of the drug to DNA gyrase. ${ }^{73}$ Whether this is related to reduced permeability through the cell membrane is not yet clear.

\section{Frequency of resistance to the 4-quinolones}

When plasmid-mediated resistance does not exist (as is the case with the 4-quinolones), the frequency at which bacteria are able to develop resistance to an antibacterial agent is important in determining the efficacy of the drug. In-vitro experiments suggest that the frequency at which bacteria mutate to 4quinolone resistance is much lower for the modern fluorinated 4-quinolones than for the older drugs in this class, such as nalidixic and oxolinic acids, ${ }^{74,75}$ $\mathrm{Smith}^{75}$ found that the mutation frequency in $E$. coli strain KL16 for resistance to the older 4quinolones, such as nalidixic acid, was about $10^{-8}$ compared to less than $10^{-12}$ for the modern fluorinated drugs. Similar results with $E$. coli have also been obtained by other workers. ${ }^{76,77}$ It has been suggested that this may be because the modern drugs exert two distinct bactericidal mechanisms compared with only one for the older drugs. ${ }^{31,75,78}$

An important factor in the ability of bacteria to develop 4-quinolone resistance is the concentration of 4-quinolone to which they are exposed. Cullmann et al. ${ }^{79}$ have shown that it is fairly easy to select for 4-quinolone resistance at concentrations near the minimum inhibitory concentration (MIC) (frequency about $10^{-6}$ ) but significantly more difficult at drug concentrations of $10 \times$ MIC. Hence, it would seem important to ensure adequate serum levels to prevent the emergence of resistance during therapy. In general, gram-positive bacteria have been able to mutate to 4-quinolone resistance at higher frequencies than gram-negative bacteria. $^{31,76}$ An exception to this observation would appear to be Enterococcus faecalis as both Cullmann et $a l .^{79}$ and $\mathrm{Chin}$ and $\mathrm{Neu}^{80}$ were unable to detect any mutant strains of Ent. faecalis resistant to the 4-quinolones at concentrations of $10 \times$ MIC.

Although in-vitro experiments may give some idea of the frequency at which resistance to the 4quinolones might be anticipated to develop, it is the selection of these mutants during clinical practice that really matters. In the table it can be

Table. Bacteria developing resistance to 4-quinolones during therapy

\begin{tabular}{lll} 
Species & Quinolone* & Reference \\
\hline Escherichia coli & cip, nor & $30,35,81$ \\
Campylobacter pylori & cip, of & 82,83 \\
Citrobacter freundii & of & 84 \\
Pseudomonas aeruginosa & cip, eno & $65,85-87$ \\
P. maltophilia & of & 84 \\
Neisseria gonorrhoeae & eno & 88 \\
Staphylococcus aureus & cip & 89,90 \\
Serratia marcescens & $?$ & 43
\end{tabular}

* Quinolones were: cip, ciprofloxacin; eno, enoxacin; nor, norfloxacin; ofl, ofloxacin. 
seen that the development of resistance to the modern fluorinated 4-quinolones during therapy has been shown to have occurred in a wide range of bacterial species. Somewhat surprising are reports of $E$. coli strains which have developed resistance to the modern fluorinated 4-quinolones, ${ }^{30,35,81}$ because it is very difficult to obtain resistant mutant strains of this species in vitro. ${ }^{75,76}$ However, the mechanisms of selection for resistant becteria in clinical practice are difficult to mimic precisely in in-vitro experiments.

Such clinical reports indicate that it is possible for most bacterial species to develop resistance to the 4-quinolones during therapy. However, as most of these reports of resistance are isolated incidents, the interpretation of these reports to provide information on the frequency at which resistance is likely to develop clinically is difficult. The clinical trials conducted during the development of the 4quinolones provide some information. The phaseII and phase-III trials of ciprofloxacin suggested that the frequency of resistance to the modern drugs might be low; thus, only in five out of 1993 infections treated with the drug were the causative organisms considered to have developed resistance to ciprofloxacin during treatment. ${ }^{91}$

The monitoring of bacterial susceptibility to the 4-quinolones once introduced also serves to provide epidemiological information. Several large-scale studies have been carried out monitoring the susceptibility of bacterial pathogens to the 4quinolones since they have become available and very little resistance to the modern 4-quinolones was observed $;^{92-95}$ in general, resistance was $<5 \%$.

Kresken and Wiedemann ${ }^{92}$ monitored nalidixicacid resistance in the Federal Republic of Germany, Austria and Switzerland from 1975 to 1986, with particular emphasis on the period between 1983 and 1986 when ofloxacin and norfloxacin became available in these countries. Despite a marked increase in the use of the 4-quinolones over that period, resistance in Enterobacteriaceae, Staph. aureus or Ent. faecalis did not increase. It should be noted that some variation in the percentage of nalidixic acid-resistant Enterobacteriaceae from different centres was observed. ${ }^{92}$ A particular problem was observed in Innsbruck where nalidixic-acid resistance was $12 \cdot 1 \%$, which appeared to result from $30.8 \%$ of $K$. pneumoniae being nalidixicacid resistant. However, as a species $P$. aeruginosa was an exception, for between 1983 and 1986 the percentage of 4-quinolone-resistant strains increased from 3 to $10 \%$. This is consistent with reports of the rapid development of ciprofloxacin resistance in $P$. aeruginosa in animal models ${ }^{96,97}$ and, clinically, elsewhere. ${ }^{85,86}$

Another survey performed in the Federal Republic of Germany by Grimm, ${ }^{93}$ testing more than 100000 bacterial strains isolated from hospitals and general practice between 1986 and 1987, found results similar to those of Kresken and Wiedemann ${ }^{92}$ for Enterobacteriaceae. Resistance to ofloxacin and ciprofloxacin was found in $<1 \%$ of strains of different species in this family. In contrast to Kresken and Wiedemann, ${ }^{92}$ Grimm did not find an increase in resistance to the 4-quinolones in $P$. aeruginosa, although he did observe a significant increase in the incidence of 4-quinolone resistance in staphylococci particularly amongst Staph epidermidis. This resistance in staphylococci was associated with multiple drug-resistance patterns and may be a cause for concern as animal models suggest that staphylococci may develop resistance to the 4-quinolones readily during therapy. ${ }^{98}$ Furthermore, a survey of methicillinresistant Staph. aureus (MRSA) from various centres in the world found the incidence of ciprofloxacin resistance to be as high as $17 \%{ }^{99}$ An Israeli hospital has reported resistance to the 4quinolones in 45 of 50 clinical isolates of MRSA, although none of the 20 MSSA tested during the same period were 4-quinolone-resistant. ${ }^{100}$ It should be noted, however, that none of the MRSA had actually developed resistance to the 4-quinolones during therapy. ${ }^{100}$

In other bacterial species problems may also exist. The frequency of resistance to the 4-quinolones may be increasing in $B$. fragilis. A survey in Japan, in which more than 300 isolates of this species were examined, found that the frequency of 4-quinolone resistance was significantly higher in isolates collected in 1986-1987 than in isolates collected during 1983-1984. ${ }^{44}$

At present, results from large-scale sensitivity surveys suggest that the incidence of 4-quinolone resistance in bacteria is still rare, although it seems to be occurring with increasing frequency in certain species such as $P$. aeruginosa, staphylococci (particularly multi-resistant organisms) and $B$. fragilis. It will be interesting to monitor the frequency of resistance to the 4-quinolones over the next few years as more 4-quinolones become available and the use of this class of antibacterial agents increases. It should also be noted that it has been suggested that 4-quinolone-resistant strains may be less pathogenic ${ }^{31}$ because of their reduced virulence. ${ }^{72,96,101}$ Further investigation of this phenomenon will be required before this is conclusively shown to be the case. 


\section{Conclusions}

The 4-quinolones are broad-spectrum antibiotics for which plasmid-mediated resistance has not yet been identified. Bacteria are able to develop resistance to these drugs via chromosomal mutations which result in an altered target (DNA gyrase) or reduced uptake of the drug (associated with alterations in the outer membrane). Resistance to

\section{REFERENCES}

1. Gellert M, Mizuuchi K, O’Dea M H, Nash H A. DNA gyrase: An enzyme that introduces superhelical turns into DNA. Proc Natl Acad Sci USA 1976; 73 : 38723876.

2. Wang J C. DNA topoisomerases. Annu Rev Biochem 1985; 54: 665-697.

3. Drlica K, Franco R J. Inhibitors of DNA topoisomerases. Biochemistry 1988; 27: 2254-2259.

4. Smith G R. DNA supercoiling: another level for regulating gene expression. Cell 1981; 24: 593-600.

5. Fisher L M. DNA supercoiling and gene expression. Nature 1984 ; 307: 686-687.

6. Higgins N P, Peebles C L, Sugino A, Cozzarelli N R. Purification of subunits of Escherichia coli DNA gyrase and reconstitution of enzymatic activity. Proc Natl Acad Sci USA 1978; 75: 1773-1777.

7. Cozzarelli N R. DNA gyrase and the supercoiling of DNA. Science $1980 ; 207: 953-960$.

8. Kirkegaard K, Wang J C. Mapping the topography of DNA wrapped around gyrase by nucleolytic digestion and chemical probing of complexes of unique DNA sequences. Cell 1981; 23: 721-729.

9. Sugino A, Cozzarelli N R. The intrinsic ATPase of DNA gyrase. J Biol Chem 1980; 255: 6299-6306.

10. Gellert M, Mizuuchi K, O'Dea M H, Itoh T, Tomizawa JI. Nalidixic acid resistance: A second genetic character involved in DNA gyrase activity. Proc Natl Acad Sci USA 1977; 74: 4772-4776.

11. Steck T R, Drlica K. Bacterial chromosome segregation: Evidence for DNA gyrase involvement in decatenation. Cell 1984; 36: 1081-1088.

12. Lesher G Y, Froelich E J, Gruett M D, Bailey J H, Brundage R P. 1,8-Naphthyridine derivatives, a new class of chemotherapeutic agents. J Med Chem 1962; 5: 1063-1065.

13. Moorhead P J, Parry H E. Treatment of sonne dysentery. Br Med J 1965; 2: 913-915.

14. Stamey T A, Nemoy N J, Higgins $H$. The clinical use of nalidixic acid; a review and some observations. Invest Urol $1969 ; 6$ : 582-592.

15. Phillips I, King A, Shannon K. In vitro properties of the quinolones. In: Andriole V (ed) The Quinolones. London, Academic Press. 1988: 83.

16. Amyes S G B. The success of plasmid-encoded resistance genes in clinical bacteria. An examination of plasmidmediated ampicillin and trimethoprim resistance genes and their resistance mechanisms. $J$ Med Microbiol $1989 ; 28: 73-83$.

17. Panhotra B R, Desai B, Sharma P L. Nalidixic-acidresistant Shigella dysenteriae I. Lancet 1985; $1: 763$.

18. Munshi M H, Sack D A, Haider K, Ahmed Z V, Rahaman M M, Morshed M G. Plasmid-mediated resistance to the 4-quinolones has been shown to occur clinically but its occurrence is still relatively infrequent. However, the incidence of resistance appears to be increasing in certain groups such as staphylococci and pseudomonads. It is to be hoped that, with appropriate use and dosing, the incidence of resistance to the modern fluorinated 4-quinolones will remain relatively low in the near future.

nalidixic acid in Shigella dysenteriae type I. Lancet 1987; $2: 419-421$.

19. Crumplin G C. Plasmid mediated resistance to nalidixic acid and new 4-quinolones? Lancet 1987; 2 : 854-855.

20. Levy J, Verhaegen G, van Naekten C et al. Genetic basis of nalidixic acid resistance in Shigella dysenteriae type I from Central Africa. Abstracts of the 28th Interscience Conference on Antimicrobial Agents and Chemotherapy $1988: 266$.

21. Hooper D C, Wolfson J S, Ng E Y, Swartz M N. Mechanisms of action and resistance to ciprofloxacin. Am J Med 1987; 82 suppl 4a: 12-20.

22. Hane $\mathbf{M ~ W}$, Wood T H. Escherichia coli K12 mutants resistant to nalidixic acid: Genetic mapping and dominance studies. J. Bacteriol 1969; 99 : 238-241.

23. Smith J T. The 4-quinolone antibacterials. In: Greenwood D, O'Grady F (eds) Scientific basis of antimicrobial chemotherapy. Cambridge, Cambridge University Press. 1985: 63.

24. Nakamura S, Nakamura M, Kojima T, Yoshida H. gyr $A$ and $g y r B$ mutations in quinolone-resistant strains of Escherichia coli. Antimicrob Agents Chemother 1989; 33: 254-255.

25. Crumplin G C, Smith J T. The effect of R-factor plasmids on host-cell responses to nalidixic acid I. Increased susceptibility of nalidixic acid-sensitive hosts. J Antimicrob Chemother 1981; 7: 379-388.

26. Weisser J, Wiedemann B. Elimination of plasmids by enoxacin and ofloxacin at near inhibitory concentrations. J. Antimicrob Chemother 1986; 18: 575-583.

27. Michel-Briand Y, Uccelli V, Laporte J M, Plessiat P. Elimination of plasmids from Enterobacteriaceae by 4-quinolone derivatives. J Antimicrob Chemother 1986; 18: 667-674.

28. Weisser J, Wiedemann B. Inhibition of R-plasmid transfer in Escherichia coli by 4-quinolones. Antimicrob Agents Chemother 1987; 31 : 531-534.

29. Mehtar S, Blakemore $P H$, Ellis $K$. In vivo curing of plasmids from multi-drug-resistant Serratia marcescens by ciprofloxacin. Am J Med 1987; 82 suppl 4a: 55-57.

30. Lewin C S, Smith J T, Hamilton-Miller J M T, Brumfitt W. Gain of antibiotic sensitivity accompanying emergence of clinical ciprofloxacin resistance. Lancet 1988; 1: $1462-1463$.

31. Smith $J$ T, Lewin C S. Chemistry and mechanisms of action of the quinolone antibacterial. In: Andriole $\mathrm{V}$ (ed) The Quinolones. London, Academic Press. 1988: 23.

32. Novick R P. Extrachromosomal inheritance in bacteria. Bacteriol Rev 1969; 33: 210-235.

33. Uhlin B E, Nordstrom K. Preferential inhibition of plasmid replication in vivo by altered DNA gyrase activity in Escherichia coli. J Bacteriol 1985; 162: 855857. 
34. Hooper D C, Wolfson J S, Souza K S, Tung C, McHugh G L, Swartz M N. Genetic and biochemical characterization of norfloxacin resistance in Escherichia coli. Antimicrob Agents Chemother 1986; 29 : 639-644.

35. Aoyama H, Sato K, Kato T, Hirai K, Mitsuhashi S. Norfloxacin resistance in a clinical isolate of Escherichia coli. Antimicrob Agents Chemother 1987; 31: 1640-1641.

36. Chapman J S, Bertasso A, Georgopapapdakou N H. Fleroxacin resistance in Escherichia coli. Antimicrob Agents Chemother 1989; 33: 239-241.

37. Rella M, Haas D. Resistance of Pseudomonas aeruginosa PAO to nalidixic acid and low levels of $\beta$-lactam antibiotics: Mapping of chromosomal genes. Antimicrob Agents and Chemother 1982; 22 : 242-249.

38. Hirai K, Suzue S, Irikura T, Iyobe S, Mitsuhashi S. Mutations producing resistance to norfloxacin in Pseudomonas aeruginosa. Antimicrob Agents Chemother $1987 ; 31$ : 582-586.

39. Inoue Y, Sato K, Fujii T et al. Some properties of DNA gyrase from Pseudomonas aeruginosa PA01 and its nalidixic acid-resistant mutant. J Bacteriol 1987; 169 : 2322-2325.

40. Robillard N J, Scarpa A L. Genetic and physiological characterization of ciprofloxacin resistance in Pseudomonas aeruginosa PAO. Antimicrob Agents Chemother $1988 ; 32$ : 535-539.

41. Setlow J K, Cabrera-Juarez E, Albritton W L, Spikes D, Mutschler A. Mutations affecting gyrase in Haemophilus influenzae. J Bacteriol 1985; 164 : 525-534.

42. Aoyama H, Sato K, Fujii T, Fulimaki K, Inoue $M$, Mitsuhashi S. Purification of Citrobacter freundii DNA gyrase and inhibition by quinolones. Antimicrob Agents Chemother 1988; 32 : 104-109.

43. Fujimaki K, Fujii $\mathrm{T}$, Aoyama $\mathrm{H}$, et al. Quinolone resistance in clinical isolates of Serratia marcescens. Antimicrob Agents Chemother 1989; 33: 785-787.

44. Kato N, Miyauchi M, Muto Y, Watanabe K, Ueno $K$. Emergence of fluoroquinolone resistance in Bacteroides fragilis accompanied by resistance to $\beta$-lactam antibiotics. Antimicrob Agents Chemother 1988; 32: 14371438.

45. Yoshida H, Kojima T, Yamagishe J, Nakamura S. Quinolone-resistant mutations of the gyrA gene of Escherichia coli. MGG 1988; 211:1-7.

45a. Cullen M E, Wyke A M, Kuroda R, Fisher L M. Cloning and characterization of a DNA gyrase gene from Escherichia coli that confers clinical resistance to 4quinolones. Antimicrob Agents Chemother 1989; 33: 886-894.

46. Horowitz D S, Wang J C. Mapping the active site tyrosine of Escherichia coli DNA gyrase. J Biol Chem 1987; 262: 5339-5344.

47. Yamagishi J, Yoshida H, Yamayoshi M, Nakamura S. Nalidixic acid-resistant mutations of the $\operatorname{gyr} B$ gene of Escherichia coli. MGG 1986; 204: 367-373.

48. Inoue S, Ohue T, Yamagishi J, Nakamura S, Shimizu M. Mode of incomplete cross-resistance among pipemidic, piromidic and nalidixic acids. Antimicrob Agents Chemother 1978; 14: 240-245.

49. Smith J T. Mutational resistance to the 4-quinolone antibacterial agents. Eur J Clin Microbiol 1984; 3: $347-$ 350.

50. Fu K P, Grace M E, McCloud S J, Gregory F J, Hung P P. Discrepancy between the antibacterial activities and inhibitory effects on Micrococcus luteus DNA gyrase of 13 quinolones. Chemotherapy 1986; 32 : 494 498.

51. Zweerink M M, Edison A. Inhibition of Micrococcus luteus DNA gyrase by norfoxacin and 10 other quinolone carboxylic acids. Antimicrob Agents Chemother 1986; 29: 598-601.

52. Piddock $\mathbf{L} \mathbf{J} \mathrm{V}$, Wise $R$. Mechanisms of resistance to quinolones and clinical perspectives. $J$ Antimicrob Chemother $1989 ; 23$ : 475-480.

53. Takahata M, Nishino T. DNA gyrase of Staphylococcus aureus and inhibitory effect of quinolones on its activity. Antimicrob Agents Chemother 1988; 32: 1192-1195.

54. Hirai K, Aoyama H, Irikura T, Iyobe S, Mitsuhashi S. Differences in susceptibility to quinolones of outer membrane mutants of Salmonella typhimurium and Escherichia coli. Antimicrob Agents Chemother 1986; 29: $535-538$.

55. Crumplin G C. Quinolone/ureidopenicillin cross-resistance in gram negative bacteria. Lancet $1987 ; 2$ : 1519 1520 .

56. Bedard J, Wong S, Bryan L E. Accumulation of enoxacin by Escherichia coli and Bacillus subtilis. Antimicrob Agents Chemother 1987; 31 : 1348-1354.

57. Chapman J S, Georgopapadakou N H. Routes of quinolone permeation in Escherichia coli. Antimicrob Agents Chemother 1988 ; 32: 438-442.

58. Cohen S P, Hooper D C, Wolfson J S, Souza K S, McMurry L M, Levy S B. Endogenous active efflux of norfloxacin in susceptible Escherichia coli. Antimicrob Agents Chemother 1988; 32: 1187-1191.

59. Chamberland S, Bayer A S, Schollaardt T, Wong S A, Bryan L E. Characterization of mechanisms of quinolone resistance in Pseudomonas aeruginosa strains isolated in vitro and in vivo during experimental endocarditis. Antimicrob Agents Chemother 1989; 33: 624-634.

60. Hooper D C, Wolfson J S, Souza K S, Ng E Y, McHugh G L, Swartz M N. Mechanisms of quinolone resistance in Escherichia coli: characterization of $n f x B$ and $c f x B$, two mutant resistance loci decreasing norfloxacin accumulation. Antimicrob Agents Chemother 1989; 33: 283-290.

61. Hirai K, Aoyama H, Suzue S, Irikura T, Iyobe $S$, Mitsuhashi S. Isolation and characterization of norfloxacin-resistant mutants of Escherichia coli K12. Antimicrob Agents Chemother 1986; 30: 248-253.

62. Piddock L J V, Wijnands W J A, Wise R. Quinolone/ ureidopenicillin cross-resistance. Lancet 1987; 2 : 907.

63. Sanders C C, Sanders W E, Goering R V, Werner V. Selection of multiple antibiotic resistance by quinolones, beta-lactams and aminoglycosides with special reference to cross-resistance between unrelated drug classes. Antimicrob Agents Chemother 1984; 26: 797801.

64. Gutmann L, Williamson $\mathrm{R}$, Moreau $\mathrm{N}$ et al. Crossresistance to nalidixic acid, trimethoprim and chloramphenicol associated with alterations in outer membrane proteins of Klebsiella, Enterobacter and Serratia. J Infect Dis 1985; 151 : 501-507.

65. Traub W H. Incomplete cross-resistance of nalidixic acid and pipemidic acid-resistant variants of Serratia marcescens against ciprofloxacin, enoxacin and norfloxacin. Chemotherapy $1985 ; 31: 34-39$.

66. Sanders C C, Watanakunakorn C. Emergence of resistance to beta-lactams, aminoglycosides and quinolones during combination therapy for infection due to Serratia marcescens. J Infect Dis 1986; 153 : 617-619. 
67. George A M, Levy S B. Gene in the major cotransduction gap of the Escherichia coli $\mathrm{K}-12$ linkage map required for the expression of chromosomal resistance to tetracycline and other antibiotics. $J$ Bacteriol 1983; 155: $541-548$.

68. Cohen S P, McMurry L M, Levy S B. marA locus causes decreased expression of OmpF porin in multipleantibiotic-resistant (mar) mutants of Escherichia coli. $J$ Bacteriol 1988; 170 : 5416-5422.

69. Hrebenda J, Helezsko H, Brzostek K, Bieleki J. Mutation affecting resistance of Escherichia coli $\mathrm{K} 12$ to nalidixic acid. J Gen Microbiol 1985; 131 : 2285-2292.

70. George A M, Levy S B. Amplifiable resistance to tetracycline, chloramphenicol and other antibiotics in Escherichia coli: Involvement of non-plasmid-determined efflux of tetracycline. $J$ Bacteriol 1983; 155: 531-540.

71. Daikos G L, Lolans V T, Jackson G G. Alterations in outer membrane proteins of Pseudomonas aeruginosa associated with selective resistance to quinolones. Antimicrob Agents Chemother 1988; 32: 785-787.

72. Legakis N J, Tzouvelekis L S, Makris A, Kotsifaki H. Outer membrane alterations in multiresistant mutants of Pseudomonas aeruginosa selected by ciprofloxacin. Antimicrob Agents Chemother 1989; 33: 124-127.

73. Kaatz G W, Seo S M. Mechanisms of ciprofloxacin resistance in Staphylococcus aureus. Abstracts of the Annual Meeting of the American Society for Microbiology 1989; A-98.

74. Wolfson J S, Hooper D C. The fluoroquinolones : structures, mechanisms of action and resistance and spectra of activity in vitro. Antimicrob Agents Chemother 1985; 28 : 581-586.

75. Smith J T. Frequency and expression of mutational resistance to the 4-quinolone antibacterials. Scand $J$ Infect Dis 1986; 49 suppl: 115-123.

76. Limb D I, Dabbs D J W, Spencer R C. In vitro selection of bacteria resistant to the 4-quinolone agents. $J$ Antimicrob Chemother 1987; 19: 65-71.

77. Barry A L, Gardiner R V, Packer R R. Resistance to ten different fluoroquinolone antibiotics following in vitro exposures to nalidixic acid. Diagn Microbiol Infect Dis $1987 ; 6: 77-79$.

78. Smith J T. Awakening the slumbering potential of the 4quinolone antibacterials. Pharm J 1984; 233: 299-305.

79. Cullmann W, Stieglitz M, Baars B, Opferkuch W. Comparative evaluation of recently developed quinolone compounds - with a note on the frequency of resistant mutants. Chemotherapy $1985 ; 31$ : 19-28.

80. Chin N X, Neu H C. Ciprofloxacin a quinolone carboxylic acid compound active against aerobic and anaerobic bacteria. Antimicrob Agents Chemother 1984; 25 : 319326.

81. Sato K, Inoue $Y$, Fujii T, Aoyama $H$, Inoue M, Mitsuhashi S. Purification and properties of DNA gyrase from a fluoroquinolone-resistant strain of Escherichia coli. Antimicrob Agents Chemother 1986; 30: 777-780.

82. Glupczynski Y, Labbe M, Burette A, Delmee M, Avesani V, Bruck C. Treatment failure of ofloxacin in Campylobacter pylori infection. Lancet 1987; 1: 1096.

83. Stone J W, Wise R, Donovan I A, Gearty J. Failure of ciprofloxacin to eradicate Campylobacter pylori from the stomach. J Antimicrob Chemother 1988; 22: 92-93.

84. Cheng A F, Li M K W, Ling T K W, French G L. Emergence of ofloxacin-resistant Citrobacter freundi and Pseudomonas maltophilia after ofloxacin therapy. $J$ Antimicrob Chemother 1987; 20: 283-284.
85. Roberts C M, Batten J, Hodson M E. Ciprofloxacinresistant Pseudomonas. Lancet 1985; 1 : 1442.

86. Azadian B S, Bendig J W A, Samson D M. Emergence of ciprofloxacin resistant Pseudomonas aeruginosa after combined therapy with ciprofloxacin and amikacin. $J$ Antimicrob Chemother 1986; 18: 771.

87. Scully B E, Neu H C, Parry M F, Mandell W. Oral ciprofloxacin therapy of infections due to Pseudomonas aeruginosa. Lancet 1986; 1 : 819-822.

88. Wagenvoort J H T, van der Willigen A $H$, van Vliet $H$ J, Michel M F, van Klingeren B. Resistance of Neisseria gonorrhoeae to enoxacin. J Antimicrob Chemother 1986; 18: 429 .

89. Humphreys H, Mulvihill E. Ciprofloxacin-resistant Staphylococcus aureus. Lancet 1985; 2 : 383.

90. Smith G M, Cashmore C, Leyland M J. Ciprofloxacinresistant staphylococci. Lancet 1985; 2 : 949.

91. Schacht P, Hullmann R. Changes of susceptibility of infecting organisms to ciprofloxacin during treatment. Abstracts of the Congress on Bacterial and Parasitic Drug Resistance Bangkok 1986: 109.

92. Kresken M, Wiedemann B. Development of resistance to nalidixic acid and the fluoroquinolones after the introduction of norfloxacin and ofloxacin. Antimicrob Agents Chemother 1988; 32: 1285-1288.

93. Grimm H. Monitoring resistance to new quinolones and resistance patterns in the first two years following the introduction of these drugs. International Symposium on Ciprofloxacin, Dresden East Germany 1988.

94. Lovering A M, Bywater M J, Holt H A, Champion H M, Reeves D S. Resistance of bacterial pathogens to four aminoglycosides and six other antibacterials and prevalence of aminoglycoside modifying enzymes in 20 UK centres. J Antimicrob Chemother 1988; 22 : 823840.

95. Tillotson G S, Herbert J J F. National surveillance of susceptibility of various antimicrobial agents including a fluoroquinolone. Abstracts of the 4th European Congress of Clinical Microbiology 1989: 431.

96. Fernandes P B, Hanson C W, Stamm J M, Vojtko C, Shipkowitz N L, St Martin E. The frequency of invitro resistance development to fluoroquinolones and the use of a murine pyelonephritis model to demonstrate selection of resistance in vivo. $J$ Antimicrob Chemother 1987; 19: 449-465.

97. Michea-Hamzehpour M, Auckenthaler R, Regamey $P$, Pechere J C. Resistance occurring after fluoroquinolone therapy of experimental Pseudomonas aeruginosa peritonitis. Antimicrob Agents Chemother 1987; 31: 1803-1808.

98. Kaatz G W, Barriere S L, Schaberg D R, Fekety R. The emergence of resistance to ciprofloxacin during treatment of experimental Staphylococcus aureus endocarditis. J Antimicrob Chemother 1987; 20 : 753-758.

99. Maple P A C, Hamilton-Miller J M T, Brumfitt W. Worldwide antibiotic resistance in methicillin-resistant Staphylococcus aureus. Lancet 1989; 1 : 537-540.

100. Shalit I, Berger S A, Gorea A, Frimerman H. Widespread quinolone resistance among methicillin-resistant Staphylococcus aureus isolates in a general hospital. Antimicrob Agents Chemother 1989; 33: 593-594.

101. Ravizzola G, Pirali F, Paolucci A et al. Reduced virulence in ciprofloxacin-resistant variants of Pseudomonas aeruginosa strains. J Antimicrob Chemother 1987; 20 : 825-829. 


\section{Note added in proof}

Ubukata et $a l^{102}$ have recently proposed that a recombinant plasmid, containing a $5 \cdot 5-\mathrm{kb}$ fragment of staphylococcal DNA believed to carry genes coding for a norfloxacin-resistant DNA gyrase, conferred resistance to both $E$. coli and Staph. aureus. This indicates that sensitivity may not always be dominant over resistance to the 4quinolones in the gyrase genes. If this does prove to be the case, it seems possible that 4-quinolone resistance could be encoded by plasmids carrying 4-quinolone-resistant DNA gyrase genes. A possible explanation for this phenomenon is that the genes for the two subunits of DNA gyrase may be closely linked in staphylococci, unlike $E$. coli, and that the recombinant plasmid carries genes for both subunits.

102. Ubukata $\mathbf{K}$, Itoh-yamashita $\mathbf{N}$, Konno $\mathbf{M}$. Cloning and expression of the nora gene for fluoroquinolone resistance in Staphylococcus aureus. Antimicrob Agents Chemother $1989 ; 33$ : $1533-1539$. 